\title{
DECOMPOSIÇÃO DE RESÍDUOS SÓLIDOS DOMICILIARES E VARIAÇÕES NA RESISTIVIDADE E CARGABILIDADE
}

\author{
César Augusto Moreira ${ }^{1}$ e Antonio Celso de Oliveira Braga ${ }^{2}$
}

Recebido em 6 outubro, 2008 / Aceito em 16 setembro, 2009

Received on October 6, 2008 / Accepted on September 16, 2009

\begin{abstract}
The applied geophysics in environmental studies is a viable and promising alternative forward of the crescent demand for new techniques of investigation, essentially in the characterization and monitoring of contaminated areas. This paper presents the results of the application of the Electrical Resistivity and Induced Polarization methods, in analysis of the area of leachate percolation from municipal solid waste landfill, in ditches with dates of programmed closing. The results suggest an association among high chargeability anomalies and residues ditches closed recently, while the low resistivity anomalies they are independent of the age of closing. The areas with high chargeability are probably related to the precipitation of iron, dissolved for attack of the leachate in soil and metallic materials present in the residues.

Keywords: leachate, chargeability, resistivity, degradation, precipitation.

RESUMO. A geofísica aplicada em estudos ambientais é uma alternativa viável e promissora diante da demanda crescente por novas técnicas de investigação, essencialmente na caracterização e monitoramento de áreas contaminadas. Este trabalho apresenta os resultados de aplicação dos métodos de Eletrorresistividade e Polarização Induzida, na análise da área de percolação de chorume proveniente de aterro de resíduos sólidos dispostos em valas com datas de fechamento programado. Os resultados sugerem uma associação entre anomalias de alta cargabilidade em valas de resíduos fechadas recentemente, enquanto que as anomalias de baixa resistividade independem da idade de fechamento das valas. As áreas com alta cargabilidade provavelmente estão relacionadas à precipitação de Ferro, dissolvido por ataque do chorume no solo e nos materiais metálicos presentes nos resíduos.
\end{abstract}

Palavras-chave: chorume, cargabilidade, resistividade, degradação, precipitação.

\footnotetext{
${ }^{1}$ Universidade Federal do Pampa, UNIPAMPA, Campus de Caçapava do Sul, Av. Pedro Anunciação, s/n, Bairro Batista, 96570-000 Caçapava do Sul, RS, Brasil - E-mail: cesarmoreira@unipampa.edu.br

2Departamento de Geologia Aplicada, IGCE, UNESP, Campus de Rio Claro, Av. 24-A, 1515, Bela Vista, Caixa Postal 178, 13506-900 Rio Claro, SP, Brasil -E-mail: acobraga@rc.unesp.br
} 


\section{INTRODUÇÃo}

A avaliação de contaminações geradas em aterro sanitários envolve uma análise ambiental integrada. Os aspectos fundamentais a serem analisados envolvem a caracterização hidrogeológica, pedológica e geológica.

0 acompanhamento de contaminantes eventualmente presentes requer sua detecção, caracterização, monitoramento e prognóstico relativos à direção de fluxo e possíveis efeitos ao ecossistema.

A aplicação de métodos geofísicos em estudos ambientais é crescente, essencialmente para a caracterização e 0 monitoramento de áreas contaminadas, devido à demanda por novas técnicas de investigação ambiental. Tais métodos são caracterizados como formas indiretas de investigação, por meio de medidas em propriedades físicas intrínsecas aos materiais geológicos.

A possibilidade de aquisição de dados geofísicos em grande escala a um custo relativamente baixo, permite sua aplicação em estudos ambientais, preferencialmente integrados a técnicas diretas de investigação. Entretanto, na ausência de dados diretos, os métodos geofísicos são uma alternativa no diagnóstico de áreas sob suspeita de contaminação devido a alterações em propriedades físicas do ambiente impactado.

A aplicação integrada dos métodos geofísicos de Eletrorresistividade, Polarização Induzida e Potencial Espontâneo por Lago et al. (2006) no aterro sanitário de Bauru (SP), para caracterização da área sob percolação de chorume. Os autores concluem que há uma associação entre baixos valores de resistividade e elevados valores de cargabilidade em áreas com resíduos, em contraste ao padrão natural nitidamente contrário para a área. Aparentemente há uma associação entre baixos valores de resistividade e cargabilidade em zonas com fluxo de chorume, composto caracterizado pela grande quantidade de íons e pela baixa cargabilidade.

$\mathrm{Na}$ caracterização geoquímica e geofísica do aterro sanitário municipal de Camacchio (Itália), Abu-Zeid et al. (2004) utilizam as técnicas de Tomografia Elétrica e Polarização Induzida, na tentativa de esclarecer a resposta IP geralmente observada em aterros e suas áreas adjacentes. As áreas adjacentes ao aterro com elevada permeabilidade apresentam baixa resistividade aparente pela presença de água rica em sais, concomitante a valores elevados de cargabilidade, provavelmente devido ao efeito de polarização de membrana. Resultados obtidos sobre os intervalos com resíduos também indicam baixos valores de resistividade e elevados valores de cargabilidade, neste caso associado à presença de metais sob processos de oxidação/redução, determinados em análises químicas sob a forma de elementos metálicos em solução e em suspensão na zona saturada.
A caracterização do aterro de East Anglia (Reino Unido) em termos de resistividade e cargabilidade por Aristodemou \& Thomas-Betts (2000), revelam aumento nos valores de cargabilidade na área do aterro dentro da zona saturada e com o aumento da profundidade, ao passo que tais intervalos foram caracterizados por valores de resistividade em torno de $0,3 \Omega$.m para a zona saturada e entre $0,3 \Omega$.m e $50 \Omega$.m com variação da profundidade. Ambos os parâmetros permitiram distinguir de forma clara, regiões afetadas por contaminantes.

Em trabalho de aplicação da técnica de caminhamento com leituras conjuntas de resistividade e cargabilidade, numa área contaminada por derivados de petróleo em processo de atenuação natural, Moreira \& Braga (2009) procuram relacionar anomalias nos parâmetros físicos medidos com zonas de redução e oxidação. A zona central da área contaminada apresenta baixa resistividade e cargabilidade moderada (entre $15 \mathrm{~ms}$ e $70 \mathrm{~ms}$ ), enquanto que as adjacências são caracterizadas por resistividade moderada e cargabilidade elevada (entre $70 \mathrm{~ms}$ e $150 \mathrm{~ms}$ ). Os autores associam a neoformação mineral de magnetita à zona redutora (centro da área contaminada), e de hematita às zonas periféricas (oxidantes), as anomalias detectadas, ambas localizadas na zona saturada.

Este trabalho aplica o método de Eletrorresistividade e de Polarização Induzida, por meio da técnica de caminhamento elétrico, na análise da área de abrangência do percolado proveniente da decomposição de resíduos orgânicos e sua relação com a decomposição de resíduos orgânicos, dispostos num aterro de resíduos sólidos domiciliares do tipo vala, com datas programadas de fechamento.

\section{INTERAÇÃO ENTRE 0 SOLO E CONTAMINANTES GERADOS EM ATERROS}

0 chorume pode conter substâncias tóxicas e perigosas sob a forma sólida, líquida ou gasosa e pode apresentar elevadas concentrações de cloreto, Ferro e Zinco. Os elementos com elevada mobilidade iônica geralmente apresentam altas concentrações em comparação aos elementos de baixa mobilidade iônica (Bagchi, 1987). 0 pH tende a aumentar com o tempo, pois formas ácidas iniciais tendem a estados neutralizados, com decréscimo da Demanda Química por Oxigênio (DQ0) e Demanda Biológica por Oxigênio (DBO) (Tab. 1).

A composição do material livixiado depende do tipo e da idade do resíduo depositado no aterro, taxa de infiltração de água e pH. Entretanto, a quantidade de gás e material livixiado produzido pode ser afetada pela profundidade de disposição do material, condições climáticas regionais, variações do nível freático, 
Tabela 1 - Mudanças típicas nas concentrações de chorume de acordo com a idade do resíduo (Farquhar, 1989; Birks \& Eyles, 1997) (valores em mg/l).

\begin{tabular}{|c|c|c|c|c|}
\hline \multirow{2}{*}{ Parâmetro } & \multicolumn{4}{|c|}{ Idade do resíduo } \\
\cline { 2 - 5 } & $0-5$ anos & $5-10$ anos & $10-20$ anos & $>20$ anos \\
\hline STD & $10000-25000$ & $5000-10000$ & $2000-5000$ & $>1000$ \\
\hline pH & $5-6$ & $6-7$ & $7-7.5$ & 7.5 \\
\hline DB0 & $10000-25000$ & $1000-4000$ & $50-100$ & $<50$ \\
\hline DQ0 & $15000-40000$ & $10000-20000$ & $1000-5000$ & $<1000$ \\
\hline N Amoniacal & $500-1500$ & $300-500$ & $50-200$ & $<30$ \\
\hline P total & $100-300$ & $10-100$ & & $<10$ \\
\hline Cloreto & $1000-3000$ & $500-2000$ & $100-500$ & $<100$ \\
\hline Sulfato & $500-2000$ & $200-1000$ & $50-200$ & $<50$ \\
\hline Cálcio & $2000-4000$ & $500-2000$ & $300-500$ & $<500$ \\
\hline Sódio + Potássio & $2000-4000$ & $500-1500$ & $100-500$ & $<100$ \\
\hline Magnésio + Ferro & $500-1500$ & $500-1000$ & $100-500$ & $<100$ \\
\hline Zinco + Alumínio & $100-200$ & $50-100$ & $10-50$ & $<10$ \\
\hline Alcalinidade & $10000-15000$ & $1000-6000$ & $500-2000$ & $<500$ \\
\hline
\end{tabular}

espessura do material de recobrimento e controle de entrada e saída de líquidos da área (Farquhar, 1989). É esperado que nas partes rasas do material ocorra rápida decomposição aeróbica enquanto que no corpo de resíduos em profundidade ocorra somente a decomposição parcial sob condições anaeróbicas.

Ao cruzar a base do aterro, íons metálicos em solução podem ser removidos por troca iônica, sorção ou precipitação direta no substrato, especialmente quando argiloso. Os elementos orgânicos lixiviados que adentram no sistema aqüífero anaeróbico - base do nível freático, são lentamente biodegradados, gerando ácidos que podem reagir com os materiais que estruturam 0 aqüifero, com conseqüentes alterações no fluxo geoquímico do nível (Bennett \& Siegel, 1987). Em ambientes redutores, os elementos inorgânicos como Ferro e Manganês dissolvidos no chorume, podem ser incorporados à água subterrânea.

A quantidade de água subterrânea contaminada resultante da invasão de material livixiado depende da hidrogeologia da área e da capacidade de atenuação do substrato. Este processo pode ser efetivo por diluição e dispersão em água subterrânea em aqüíferos de alta permeabilidade e com elevada condutividade hidráulica. No caso de aqüíferos menos permeáveis ou de baixa condutividade hidráulica, a contaminação carregada com sais inorgânicos pode provocar mineralizações no aqǘf́ero (Meju, 2000).

A ação de processos que resultam em alterações no estado físico das rochas, essencialmente intemperismo químico em áreas de clima tropical, pode resultar em camadas espessas de solo. A composição química dos solos residuais depende, den- tre outros fatores, dos constituintes minerais da rocha alterada. Solos originados de rochas basálticas em clima tropical são ricos em óxidos de Ferro, como hematita, goetita e argilominerais (ABGE, 1998).

A redução de óxidos de Ferro e Manganês pode conduzir quantidades significativas destes elementos às águas subterrâneas sob a forma de espécies dissolvidas, resultando em áreas de enriquecimento. As concentrações de Ferro e Manganês no aqüífero são governadas por processos de diluição, oxidaçãoredução, dissolução abiótica de elementos minerais, troca iônica, precipitação e complexação com carbono orgânico dissolvido (Christensen et al., 2001).

Elevadas concentrações de Ferro e Manganês dissolvidos na água subterrânea, originados dos sedimentos do aqüífero são demonstradas em áreas contaminadas, como 0 aterro Borden (Canadá) por Nicholson et al. (1983), no aterro Vejen (Dinamarca) por Lyngkilde \& Christensen (1992) e Heron \& Christensen (1995), e no aterro Grindsted (Dinamarca) por Bjerg et al. (1995).

\section{CARACTERIZAÇÃO DA ÁREA DE ESTUDOS}

0 aterro de Cordeirópolis está localizado no km 4,5 da rodovia Dr. Cássio de Freitas Levy, município de Cordeirópolis, Estado de São Paulo, Brasil (Fig. 1). 0 município possui aproximadamente 17.000 habitantes, com produção diária de $6 \mathrm{~m}^{3}$ de resíduos sólidos domiciliares e economia baseada na produção de revestimentos cerâmicos e cultivo de cana-de-açúcar. 


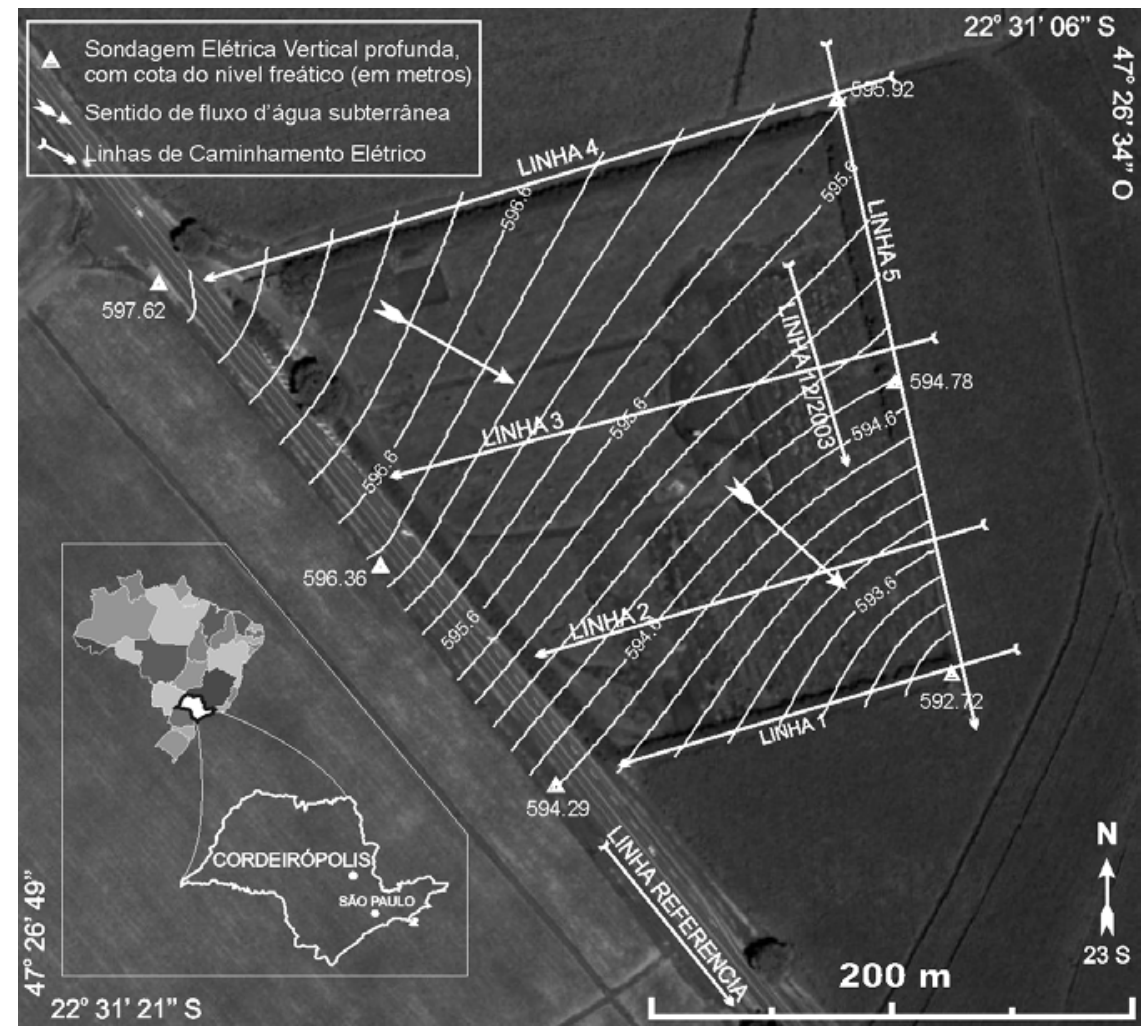

Figura 1 - Área de estudos.

A área de estudos é um aterro controlado do tipo vala, para deposição apenas de resíduos sólidos domiciliares. 0 sistema de operação consiste em valas com $5 \mathrm{~m}$ de profundidade, $4 \mathrm{~m}$ de largura e $80 \mathrm{~m}$ de comprimento, para deposição de resíduos diretamente sobre 0 solo e subseqüente cobertura com uma camada de $1 \mathrm{~m}$ de solo. Apresenta $48.400 \mathrm{~m}^{2}$ de área disponível, com início das atividades em novembro de 2001 e vida útil prevista para 20 anos.

A topografia da área é bastante plana, com declive médio de 0,5\% sentido sudeste e altitude entre $660 \mathrm{~m}$ e $659 \mathrm{~m}$. 0 aterro é cercado por fazendas de cultivo de cana-de-açúcar.

0 substrato é constituído por solo argiloso com 10m de espessura, sotoposto por um corpo de diabásio com 15m de espessura. Abaixo deste ocorrem arenitos finos e siltitos pertencentes à Formação Tatuí.

Ensaios de peneiramento, análise granulométrica conjunta e separação de minerais magnéticos em amostras de várias profundidades, caracterizam o solo da área como argiloso, além de revelar a elevada concentração de minerais metálicos no solo (Figs. 2 e 3), essencialmente óxidos de Ferro sob a forma de lâminas lateríticas milimétricas, glóbulos de goetitas e cristais parcialmente alterados de magnetita.
0 nível freático está localizado a uma profundidade média de $50 \mathrm{~m}$, com sentido de fluxo para sudeste, determinado por meio de sondagens elétricas verticais. Ensaios de condutividade hidráulica saturada de campo apontam valores médios de $10^{-4} \mathrm{~cm} / \mathrm{s}$ para 0 solo da área. Não existem poços instalados na área ou quaisquer outros sistemas de monitoramento ambiental do solo ou água subterrânea.

\section{MÉTODO}

0 método de Eletrorresistividade é baseado na geração de um campo elétrico em subsuperfície por meio da injeção de corrente elétrica $(I)$ por meio de um dispositivo eletródico representado por hastes metálicas, denominado circuito transmissor (Keller \& Frischknecht, 1966). 0 potencial elétrico $(\Delta V)$ produzido pela passagem deste campo e captado por meio de um circuito receptor, que também pode ser representado por hastes metálicas ou eletrodos impolarizáveis. A aplicação da Lei de Ohm considerando o espaçamento entre os eletrodos, representado por um fator denominado $K$, permite medidas do parâmetro resistividade aparente ( $\rho a)$ para vários níveis de profundidade (Eq. 1):

$$
\rho a=K \frac{\Delta V}{I} \Omega . m
$$




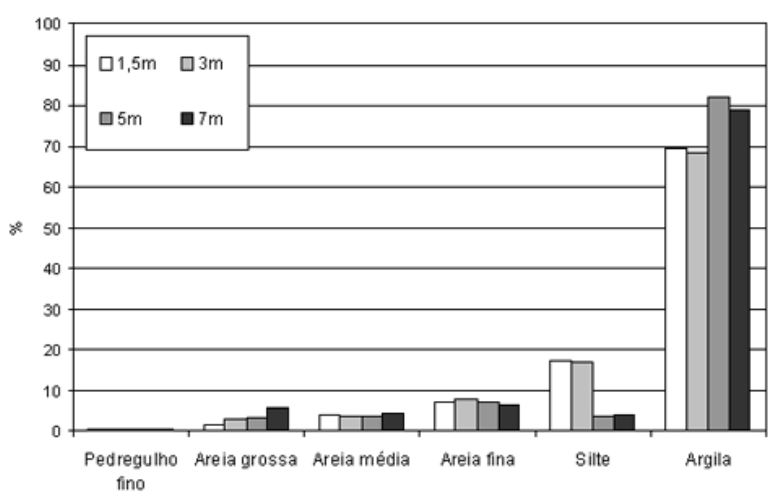

Figura 2 - Análise granulométrica em amostras de solo para quatro profundidades.

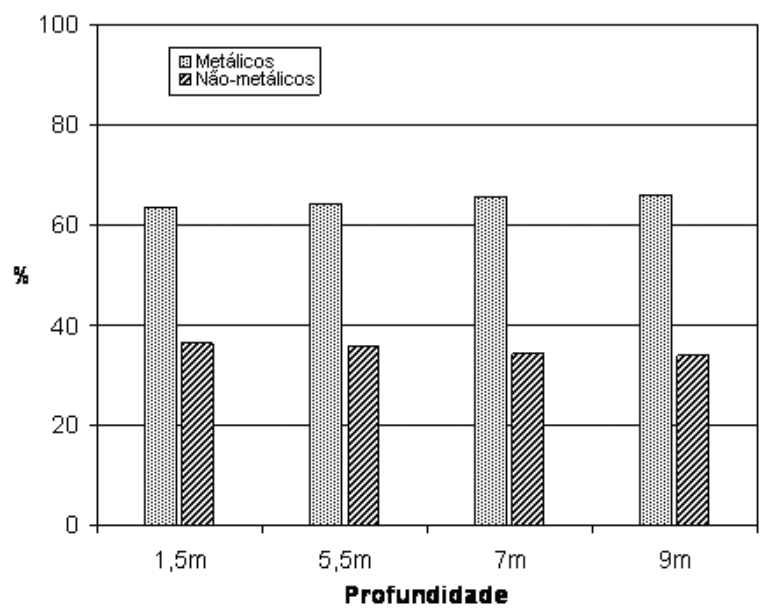

Figura 3 - Teor de minerais metálicos e não-metálicos do solo.

A Polarização Induzida (IP) é um fenômeno de estimulação de corrente elétrica, observado após o retardo ou atraso de um sinal de voltagem em materiais de subsuperfície (Sumner, 1976). Este método consiste no emprego de um dispositivo eletródico de transmissão para injeção de corrente elétrica pulsante e periódica em subsuperfície, cuja resposta é obtida por meio de um circuito receptor constituído de eletrodos impolarizáveis.

A cargabilidade é definida pelo potencial transiente variável entre dois pontos da curva de decaimento transiente normalizada pelo potencial primário. Neste trabalho foram realizadas medidas de cargabilidade no domínio do tempo, em termos de milissegundos (ms), definido como (Eq. 2):

$$
M=\frac{1}{V^{c}} \int_{t_{2}}^{t_{1}} V_{t} d t
$$

Este trabalho adota a técnica de caminhamento elétrico, baseada na realização de medidas de resistividade aparente ao longo de uma linha, com o objetivo de investigar variações em um ou mais níveis em profundidade (Keller \& Frischknecht, 1966). Dentre os diversos tipos de arranjos de campo disponíveis, o presente trabalho aplica 0 arranjo dipolo-dipolo. Este arranjo é caracterizado por utilizar espaçamento igual entre MN e AB, com deslocamento do centro de ambos os dipolos ao longo da linha.

Para a aquisição de dados foi adotado espaçamento de $5 \mathrm{~m}$ entre eletrodos e investigação em 8 níveis de profundidade. Foram utilizados 50mA de corrente de transmissão, tempo de decaimento de $10 \mathrm{~ms}$, janela única de leitura com 100ms de intervalo, tempo de aquisição de 2s, quatro ciclos de aquisição e leituras concomitantes de resistência e cargabilidade.

Foi utilizado o resistivímetro Terrameter SAS 4000, fabricado pela ABEM (Suécia). Este equipamento é calibrado para transmissão de ciclos periódicos de corrente alternada de baixa freqüência, procedimento que permite a filtragem de ruídos durante a aquisição de dados. Foram utilizados eletrodos não-polarizáveis de $\mathrm{Pb}-\mathrm{PbCl}_{2}$ tipo Petiau (Petiau, 2000), caracterizados por elevada estabilidade ao longo do tempo.

Foram realizadas 6 linhas de aquisição de dados (Fig. 1). As linhas 2 e 3 cruzam as valas de resíduos, as linhas 1,4 e 5 foram locadas nas laterais externas do aterro. A linha de referência foi locada ao lado da rodovia de acesso à área, na margem oposta ao aterro.

Os dados foram processados no programa RES2DINV (Loke \& Barker, 1996), onde foram gerados modelos de inversão em seções com distância e profundidade. Durante o processamento, foi realizada a calibração de profundidade em todas as seções, a partir da profundidade de escavação das valas.

Posteriormente, todas as medidas referentes à profundidade de $4 \mathrm{~m}$ foram tabeladas, georreferenciadas e interpoladas no programa Surfer 8.0, a partir do método de vizinhança (natural neighbor).

Neste método, os grupos iniciais são determinados pelos mais altos coeficientes de associação mútua, ou seja, para a admissão de novos membros é suficiente determinar quais os representantes de maior coeficiente de associação com um dos elementos de determinado grupo (Landim, 2004). Desta forma, a escolha deste método de interpolação foi baseada na fidelidade aos valores interpolados e limitação da superfície aos valores extremos de entrada.

\section{RESULTADOS}

Para fins de comparação com os padrões de referência da área e definiç̧ão de áreas anômalas relacionadas ao chorume proveniente da decomposição de resíduos sólidos, são apresentas as linhas de referência de resistividade e cargabilidade (Fig. 4).

0 mapa de resistividade apresenta valores bastante inferiores aos valores característicos para a área (Figs. 4 e 5). É possível 


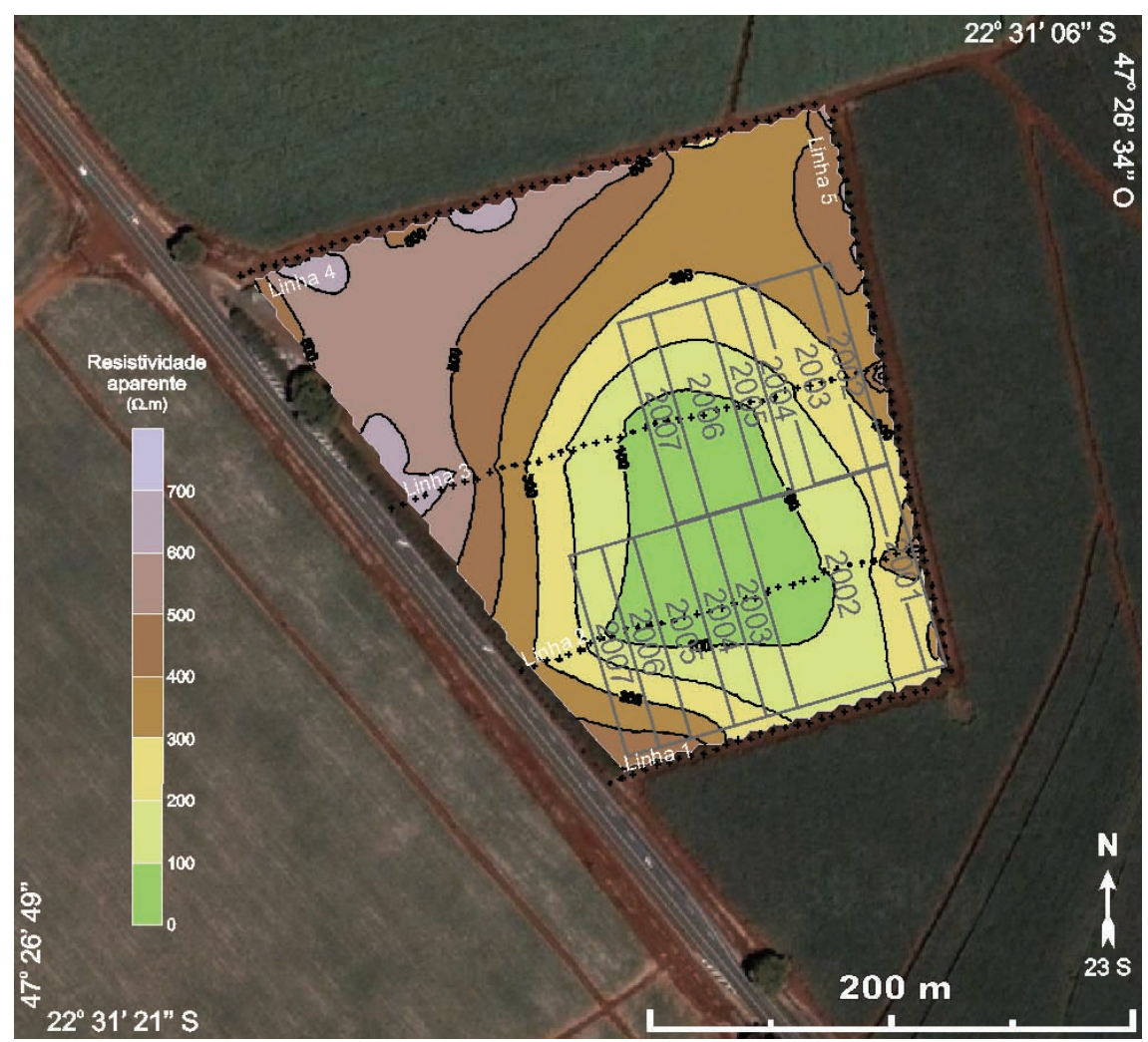

Figura 4 - Seções de referência.

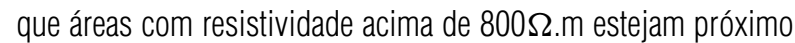
das condições naturais da área, caracterizada por valores entre $1000 \Omega$.m a $1500 \Omega$.m para $4 \mathrm{~m}$ de profundidade.

A isolinha central com valores abaixo de $100 \Omega$.m possivelmente representa a área com maior concentração de contaminantes, dado a elevada carga de sólidos totais dissolvidos (STD) que caracterizam o líquido lixiviado proveniente da decomposição de resíduos orgânicos.

0 formato desta área anômala sugere que o fluxo de chorume esteja, em princípio, condicionado à direção das valas. É possível que 0 fluxo de chorume dentro das valas seja facilitado devido à elevada porosidade e permeabilidade deste ambiente em relação ao solo da área.

A ocorrência de medidas abaixo de $100 \Omega$.m nas valas com diversos períodos de fechamento, indica que aparentemente não há uma relação entre tempo de decomposição de resíduos orgânicos e variação da resistividade elétrica.

Contudo, este intervalo de resistividade ocorre somente nas valas com fechamento em 2005, 2006 e 2007, cruzadas pela linha 3. Estas valas estão a montante das valas de 2002, $2003 \mathrm{e}$ 2004 cruzadas pela linha 2, nas quais também ocorrem medidas

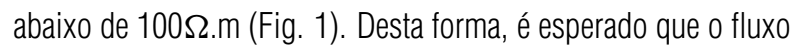

de contaminantes gerado nas valas da linha 3 intercepte as valas da linha $2 \mathrm{e}$ resulte em queda na resistividade elétrica neste último conjunto.

Grande parte da linha 1 apresenta medidas abaixo de

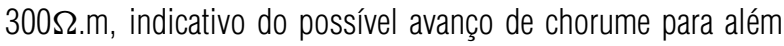
dos limites do aterro. Esta tendência também ocorre na linha 4, embora com pequena faixa de ocorrência de medidas abaixo de

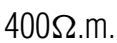

0 mapa de cargabilidade revela a ocorrência de valores bastante elevados na faixa central da linha 3 , que tende a valores médios sentido a linha 2 e a linha 1 (Fig. 6). Os maiores valores de cargabilidade, entre 60ms e 70ms, ocorrem na linha 3 e linha 2, seguidos por extremos entre 40ms e 50ms na linha 1. A área anômala é limitada pela isolinha de $20 \mathrm{~ms}$, cuja faixa de valores está presente na linha de referência a $4 \mathrm{~m}$ de profundidade.

As relações de fluxo hidráulico da área indicam que a linha 3 está a montante da linha 1. Acima das valas cruzadas pela linha 3 existe apenas uma área intocada, disponível para abertura de novas valas (Fig. 1).

Sob este contexto, a faixa de cargabilidade anômala da linha 3 pode estar associada à precipitação de elementos metálicos previamente solubilizados pelo ataque ácido do líquido lixivia- 


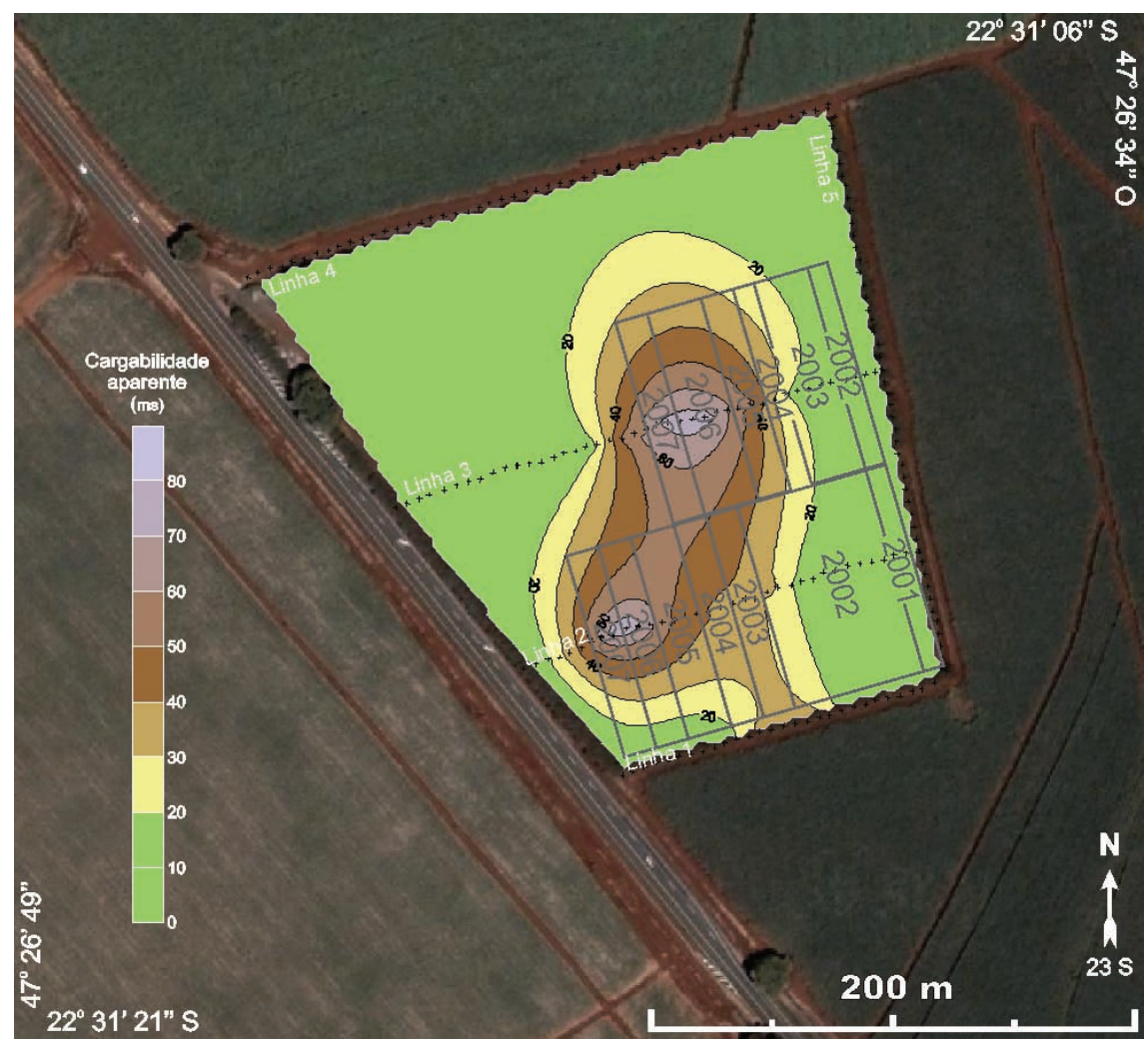

Figura 5 - Mapa de resistividade, com idade de fechamento das valas de resíduos.

do no solo em redor das valas de resíduos, concomitante a dissolução de materiais metálicos presentes nos resíduos enterrados.

0 fluxo de água meteórica infiltrada a partir das áreas a montante da linha 3 carreia oxigênio para áreas valas de resíduos, caracterizadas por condições redutoras. A dissolução de oxigênio neste ambiente ocasionar instabilidade geoquímica e conseqüente precipitação elementos metálicos, cristalizados principalmente sob a forma de minerais férricos como hematita e goetita.

A tendência de queda relativa nos valores de cargabilidade da linha 3 sentido a linha 1 pode ser reflexo do crescente estabelecimento de condições redutoras, inclusive além dos limites do aterro conforme indicado pela linha 1 , provavelmente sob influência do chorume proveniente das valas de resíduos.

Este mesmo processo deve estar ocorrendo também nas valas de resíduos cruzadas pela linha 2, devido à configuração semelhante das isolinhas. Neste caso, as anomalias de alta cargabilidade são mais restritas, possivelmente devido à limitação de áreas a montante para infiltração e fluxo d'água subterrânea.

Os valores de cargabilidade acima de $70 \mathrm{~ms}$ estão essencialmente concentrados entre as valas com fechamento entre $2006 \mathrm{e}$
2007. Considerando a percolação de águas meteóricas em toda a superfície da área das valas, é possível que os minerais metálicos neoformados por instabilidade geoquímica sejam gradativamente carreados para maiores profundidades após 2 anos de residência.

\section{CONCLUSÕES}

A caracterização da área de baixa resistividade foi possível somente após comparação com os padrões de resistividade naturais ao ambiente geológico, definidos pela linha de referência. Este é um procedimento necessário em qualquer estudo ambiental para determinação de áreas anômalas, pois os parâmetros físicos medidos pelo instrumental geofísico, especialmente pelo método de Eletrorresistividade, variam com 0 tipo de solo/rocha, características físico-químicas do fluído intersticial, grau de saturação, dentre outros fatores.

Elevadas quantidades de STD associadas ao contaminante proveniente da decomposição de material orgânico e seu comportamento no ambiente geológico, caracterizado como condutor elétrico, permitiram sua detecção pela aplicação do método geofísico de Eletrorresistividade.

A relação direta entre baixa resistividade elétrica e elevado teor de STD, correlacionados aos padrões naturais da área, per- 


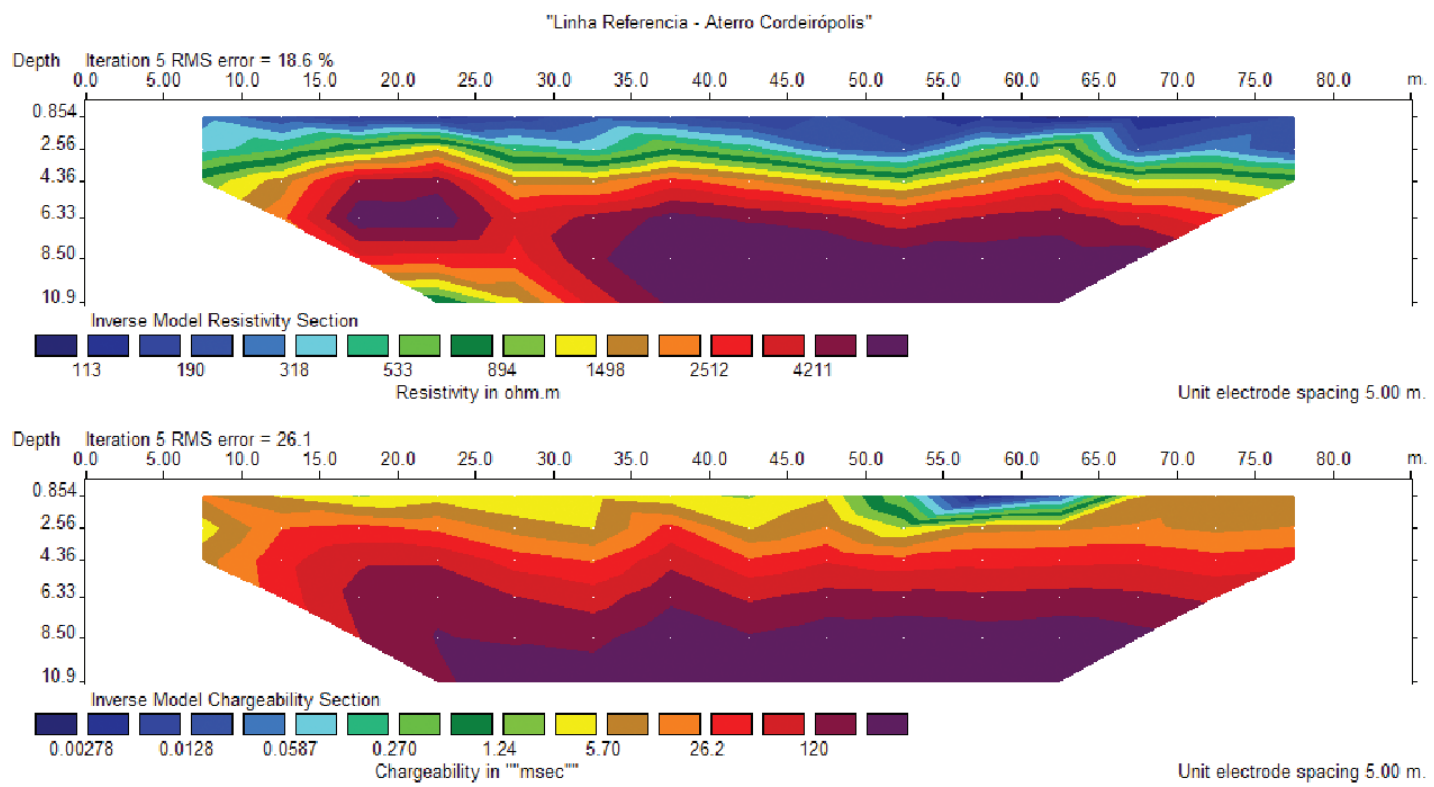

Figura 6 - Mapa de cargabilidade, com idade de fechamento das valas de resíduos.

mite a definição de zonas com elevada concentração de chorume. Tais relações permitem a definiç̧ão das áreas mais adequadas para instalação de poços de monitoramento, além de embasar projetos de remediação e recuperação de áreas degradadas.

Os resultados sugerem a geração de chorume ocorre em grande parte nas valas com fechamento entre 2005 e 2007, provavelmente devido à elevada disponibilidade de matéria orgânica. Para as demais valas, há uma tendência de aumento de resistividade, que pode ser traduzida em queda da geração de chorume, concomitante ao aumento do tempo de residência dos resíduos.

0 parâmetro físico cargabilidade, por sua vez, indica a presença de materiais passíveis de polarização, a partir dos fenômenos de polarização eletrônica ou eletrolítica. 0 fenômeno de polarização eletrônica ocorre em rochas que contenham minerais condutivos disseminados como sulfetos e metais nativos, enquanto que o fenômeno de polarização eletrolítica pode estar associado à diferença de potencial gerada pelo acúmulo de íons em pontos de estrangulamento em caminhos de fluxo de íons ou por influência de argilominerais eletricamente carregados.

Os processos de instabilidade geoquímica provocada no ambiente contaminado, por entrada de oxigênio gasoso ou dissolvido nas águas, resultam na precipitação de elementos metálicos previamente dissolvidos no contaminante líquido, fruto do estabelecimento de novas condições geoquímicas. Este precipitado mineral pode atingir concentrações passiveis de produzirem anomalias elétricas seja por indução, como no caso da polarização induzida, seja por processos de oxidação e redução e geração de potencial natural ou espontâneo.

Sob este contexto, o método de Polarização Induzida pode representar uma ferramenta para avaliação indireta das condições geoquímicas em áreas contaminadas.

Nas áreas onde as condições geoquímicas redutoras sejam estáveis é provável que ocorra o fenômeno de polarização eletrolítica, com indução de potencial elétrico em ambiente saturado por líquido rico em sais e elementos metálicos dissolvidos. A magnitude das anomalias geradas por este fenômeno é muito inferior ao produzido pelo fenômeno de polarização eletrônica, que pode em muitos casos pode se confundir com o padrão do ambiente não contaminado em redor.

Anomalias de elevada cargabilidade em aterros de resíduos sólidos podem indicar concentrações de elementos precipitados por instabilidade geoquímica em pontos localizados, além da eventual presença de resíduos metálicos. Em contrapartida, anomalias de baixa resistividade refletem áreas com elevada carga de STD, uma das principais características do chorume.

Neste sentido, os resultados da aplicação do método de Polarização Induzida em aterros de resíduos sólidos traduzem uma representação subestimada das reais dimensões da área contaminada. A relação entre elevada carga iônica e baixa resistividade permite apontar a Eletrorresistividade como uma das técnicas indiretas de investigação mais adequadas para avaliação de áreas contaminadas por chorume. 


\section{AGRADECIMENTOS}

Este trabalho foi realizado com o suporte financeiro da CAPES. Agradecemos aos técnicos Francisco Manoel Garcia Barrera, Carlos Aparecido Moreira e Fabíola Coutinho Servidoni pelo auxílio na aquisição de dados.

\section{REFERÊNCIAS}

ABGE (Associação Brasileira de Geologia de Engenharia e Ambiental). 1998. Geologia de Engenharia, São Paulo, 587 p.

ABU-ZEID N, BIANCHINI G, SANTARATO G \& VACCARO C. 2004. Geochemical characterisation and geophysical mapping of Landfill leachates: the Marozzo canal case study (NE Italy). Environmental Geology, 45: 439-447.

ARISTODEMOU E \& THOMAS-BETTS A. 2000. DC resistivity and induced polarisation investigations at a waste disposal site and its environments. Journal of Applied Geophysics, 44: 275-302.

BAGCHI A. 1987. Natural attenuation mechanisms of landfill leachate and effects of various factors on the mechanism. Waste Management Research, 5: 453-464.

BENNETT P \& SIEGEL DI. 1987. Increased solubility of quartz in water due to complexing by organic compounds. Nature, 326: 684-686.

BIRKS J \& EYLES CH. 1997. Leachate from landfills along the Niagara Escarpment. In: EYLES N (Ed.). Environmental Geology of Urban Areas. Geological Association of Canada. Canada. p. 347-363.

BJERG PL, RÜGGE K, PEDERSEN JK \& CHRISTENSEN TH. 1995. Distribution of redox-sensitive groundwater quality parameters downgradient of a landfill (Grindsted, Denmark). Environmental Science and Technology, 29: 1387-1394.

CHRISTENSEN TH, KJELDSEN P, BJERG PL, JENSEN DL, CHRISTENSEN JB, BAUN A, ALBRECHTSEN HJ \& HERON G. 2001. Biogeochemistry of landfill leachate plumes. Applied Geochemistry, 16: 659-718.

FARQUHAR GJ. 1989. Leachate: production and characterization. Canadian Journal of Civil Engineering, 16: 317-325.
HERON G \& CHRISTENSEN TH. 1995. Impact of sediment-bound iron on redox buffering in a landfill leachate polluted aquifer (Vejen, Denmark). Environmental Science and Technology, 29(1): 187-192.

KELLER GV \& FRISCHKNECHT FC. 1966. Electrical methods in geophysical prospecting. Pergamon Press, 562 pp.

LAGO AL, ELIS VR \& GIACHETI HL. 2006. Aplicação integrada de métodos geofísicos em uma área de disposição de resíduos sólidos urbanos em Bauru-SP. Revista Brasileira de Geofísica, 24(3): 357-374.

LANDIM PMB. 2004. Análise estatística de dados geológicos. São Paulo: Edunesp. 2 ed., 253 pp.

LOKE MH \& BARKER RD. 1996. Rapid least-squares inversion of apparent resistivity pseudosections by a quasi-Newton method. Geophysical Prospecting, 44: 131-152.

LYNGKILDE J \& CHRISTENSEN TH. 1992. Redox zones of a landfill leachate pollution plume (Vejen, Denmark). Journal of Contaminant Hydrology, 10: 273-289.

MEJU MA. 2000. Geoelectrical investigation of old/abandoned, covered landfill sites in urban areas: model development with a genetic diagnosis approach. Journal of Applied Geophysics, 44: 115-150.

MOREIRA CA \& BRAGA ACO. 2009. Aplicação de métodos geofísicos no monitoramento de área contaminada sob atenuação natural. Engenharia Sanitária e Ambiental, 17(2): 257-264.

NICHOLSON RV, CHERRY JA \& REARDON EJ. 1983. Migration of contaminants in groundwater at a landfill: A case study 6 . Hydrogeochemistry. Journal of Hydrology, 63: 161-176.

PETIAU G. 2000. Second generation of Lead-Lead Chloride Electrodes for Geophysical applications. Pure and Applied Geophysics, 157: 357382 .

SUMNER JS. 1976. Principles of induced polarization for geophysical exploration. Amsterdam, Elsevier Scientific, 277 pp.

\section{NOTAS SOBRE OS AUTORES}

César Augusto Moreira. Bacharel em geologia pela Universidade Estadual Paulista, UNESP/Campus de Rio Claro (2003). Doutorado em Geociências pela Universidade Estadual Paulista, UNESP/Campus de Rio Claro (2009). Atualmente trabalha como docente no curso de graduação em Geofísica na Universidade Federal do Pampa, UNIPAMPA.

Antonio Celso de Oliveira Braga. Bacharel em geologia pela Universidade Estadual Paulista, UNESP/Campus de Rio Claro (1978). Doutorado em Geociências pela Universidade Estadual Paulista, UNESP/Campus de Rio Claro (1997). Trabalhou no Instituto de Pesquisas Tecnológicas do Estado de São Paulo, IPT (1978 a 1995). Desde 1998 é Professor Doutor do Departamento de Geologia Aplicada, IGCE/UNESP, Rio Claro, atuando com geofísica aplicada à hidrogeologia e estudos ambientais, envolvendo os métodos geoelétricos. 